\title{
Decoding travellers' willingness to pay more for green travel products: closing the intention-behaviour gap
}

\begin{abstract}
In the complex context of green consumption, researchers have examined the impact of many variables on pro-environmental behaviours, but have paid little attention to the effects of specific combinations of factors. This study fills this gap, using innovative methods to show how a combination of demographic variables, values, normative influence, personality traits and beliefs can stimulate travellers' willingness to pay more (WLP), using one qualitative and two quantitative studies. In a strong methodological contribution, we develop a model based on complexity theory, which was validated using fuzzy-set qualitative comparative analysis (fsQCA) of 642 travellers. The results indicate that our integrated model has a favourable level of predictive power for travellers' behaviour. Our findings suggest that no single factor is sufficient to drive travellers' willingness to pay more, but the results of the fsQCA in four configurations propose eight causal recipes for achieving high WLP. Alongside its significant methodological contribution, our study makes strong theoretical and practical contributions, including how managers can target their green travel products more effectively.
\end{abstract}

Keywords: Willingness to pay more, theory of planned behaviour, configurational modelling, personality traits, complexity theory, fsQCA. 


\section{Introduction}

The phenomenon of green consumption has emerged as a significant new frontier for researchers and marketers in the field of customer behaviour studies (Lai \& Cheng, 2016; Brach, Walsh, \& Shaw, 2018; Rahman, Chen, \& Reynolds, 2020). Early research has paid considerable attention to the term "green" in the context of hospitality and tourism, where it has great significance (e.g. Han, Meng \& Kim, 2017; Kim \& Han, 2010; Morren \& Grinstein, 2016; Lee \& Cheng, 2018; Gupta, Dash, \& Mishra, 2019). The rapid development of ecofriendly travel products has led to major developments in the hospitality and tourism industry (eMarketer, 2017; Gao \& Mattila, 2016; Yadav, Balaji, \& Jebarajakirthy, 2019), making it one of the top concerns for practitioners and researchers in the field (Wang, Wang, Wang, Li, \& Zhao, 2018). Today's managers are paying closer attention to the hospitality industry's impact on the environment (Kang, Stein, Heo, \& Lee, 2012; Line \& Hanks, 2016; Akhtar, Khan, Frynas, Tse, \& Rao-Nicholson, 2018; Peng \& Chen, 2019). As a result, tourism and hospitality firms have introduced programmes to reduce the negative environmental impacts of their products (Martínez García de Leaniz et al., 2018; Gil-Soto, Armas-Cruz, Morini-Marrero, \& Ramos-Henríquez, 2019). Since a major goal of any tourism and hospitality firm is to improve consumers' behaviour vis-à-vis their business (Buhalis \& Leung, 2018), some companies have developed sustainability programmes, guidelines and plans aimed at improving their consumers' positive behaviour or intentions (Han, 2015; Moscardo \& Hughes, 2018). Previous studies have confirmed there are organisational benefits of investing in green initiatives such as environment-friendly travel products (Testa \& Iraldo, 2010; Hsiao, Chuang, \& Huang, 2018; Piriyapada \& Wang, 2015; Seetaram, Song, Ye, \& Page, 2018).

The growing popularity of green travel products has resulted in an emerging body of literature investigating the variables that affect travellers' intention to buy and willingness to pay more for these products(e.g. Gao \& Mattila, 2016; Wang et al., 2018; Zhao, Geng, Liu, Tao, \& Xue, 
2018; Line \& Hanks, 2016). In one study, Wang and Jia (2012) found that $73.6 \%$ of respondents were willing to pay $\$ 10.72$ to visit an eco-friendly park where current entry costs were $\$ 3.02$. Han, Hsu, \& Sheu (2010) advised hospitality and tourism scholars to expand their study of consumers' decision-making processes relating to paying more for eco-friendly products.

The pricing of green products (non-market goods), has been investigated in a number of different fields (Piriyapada \& Wang, 2015; Herrero, Sanz, Bedate, \& Barrio, 2012; Seetaram et al., 2018). Willingness to pay more (WTP) has been investigated in contexts including natural parks (Goh, Ritchie, \& Wang, 2017), the conservation of natural resources (e.g. Schuhmann et al., 2019; Piriyapada \& Wang, 2015) and eco-friendly tourism products (Eustice, McCole, \& Rutty, 2019). A few studies have also considered how personality traits and the values that influence customers' behaviour are implicit criteria for buying decisions (Gonçalves, Lourenço, \& Silva, 2016). Previous studies on pro-environmental intentions have applied different theories such as value-belief-norm (VBN) theory (Stern, Dietz, Abel, Guagnano, \& Kalof, 1999), the theory of consumption values (TCV) (Sheth, Newman, \& Gross, 1991) and the theory of planned behaviour (TPB) (Ajzen, 1985) to predict consumers' behavioural intentions toward eco-friendly products, which is a complex phenomenon (Olya \& Akhshik, 2019). Several studies have also extended, integrated or modified the relevant theories in line with their suggested conceptual frameworks predicting eco-friendly behaviour (e.g. Han, 2015; Kiatkawsin \& Han, 2017; Do Paço, Shiel, \& Alves, 2019).

Despite these various models, Olya and Akhshik (2019) described eco-friendly behaviour in hospitality and tourism as a "black-box", and as an understudied area that required more research using innovative theoretical and methodological techniques to validate and conceptualise eco-friendly behaviour conceptual frameworks (Olya \& Akhshik, 2019; Kiatkawsin \& Han, 2017). 
Most prior research on this issue has investigated the "net effect" of indicators on eco-friendly behaviour without explaining the complexity of consumers' behaviours. However, focusing on net effects and symmetric may be misleading, as such effects do not apply to all cases in the dataset, meaning the association between two factors is rather unlikely to be of symmetrical form (Woodside, 2014); neither does investigating the net effect provide accurate results on the complex process of buying behaviour (Olya \& Akhshik, 2019). Previous studies have neglected the fact that customer behaviour does not shift until the complex antecedents of the behaviour reach a specific "tipping point" (Olya \& Akhshik, 2019). A direct guideline that overlooks the complex associations between indicators can lead to unexpected outcomes, which may cost more than the issue itself.

The main aim of the present research is therefore to fill this gap by conceptualising and testing a configurational framework utilising fuzzy-set qualitative comparative analysis (fsQCA) and complexity theory, which is a state-of-the-art method of investigating the stimulation of willingness to pay more for green/eco-friendly travel products (WLP). A distinctive approach is adopted to provide a complete model for investigating the drivers of WLP. The study makes three major contributions to the travel and tourism literature: (1) by providing a robust framework that can deliver a comprehensive understanding of travellers' behaviour and willingness to pay more by combining demographic variables and personality traits and by using the three theories outlined above (VBN, TCV and TPB); (2) by examining the role of study variables in predicting travellers' willingness to pay more for green travel products and introducing a new approach (i.e. fsQCA) to investigate such products; and (3) by accounting for the complexity of the associations between eco-friendly travel product indicators, and empirically explaining how these indicators contribute to the development of such products, offering a list of managerially actionable steps for their creation and management. As a result, the findings have significant implications for travel and tourism firms seeking practical ways 
to identify demand for eco-friendly products, and promote the idea that travel and tourism firms should invest in green activities.

\section{Literature review}

\section{Overarching theories}

The number of studies exploring green products has increased significantly over the past few years. Researchers have adopted a number of overarching theories such as VBN theory (e.g. Fornara, Pattitoni, Mura, \& Strazzera, 2016; Kiatkawsin \& Han, 2017; Landon, Woosnam, \& Boley, 2018), TPB (e.g. Lee, Hsu, Han, \& Kim, 2010; Morren \& Grinstein, 2016; Yadav \& Pathak, 2017; Wang et al., 2018), TCV (e.g. Lin \& Huang, 2012; Gonçalves et al., 2016), the norm activation model (e.g., Kiatkawsin \& Han, 2017; Esfandiar, et al., 2020) and complexity theory (e.g. Olya \& Akhshik, 2019; Olya et al., 2019).

Scholars have argued that no single theory, such as the TPB or VBN model, is sufficient to develop a conceptual pro-environmental behaviour model. This is mainly because of the complexity of pro-environmental behaviours and the complex combination of multiple contextual factors. Some studies have used TPB to explain the antecedents of the proenvironmental behaviours of visitors and travellers (Nguyen, Lobo, \& Greenland, 2016; Dolnicar, Knezevic Cvelbar, \& Grünet, 2017; Goh et al., 2017), while others have expanded the theory to predict the behavioural intentions of internet game users (Zach \& Lissitsa, 2016), or the pro-environmental behaviours of cruise customers (Han et al., 2017). Other researachers have drawn on multiple theories like TPB and VBN to examine whether visitors are willing to pay for conservation (Roberts, Hanley, \& Cresswell, 2017), and to determine the proenvironmental behaviours of green hotel customers. VBN theory and the antecedents of 
expectancy theory have also been merged to determine the pro-environmental behaviours of travellers (Kiatkawsin \& Han, 2017).

These studies have shown that modifying, expanding and merging current theories is necessary, but do not sufficiently model the complexity of green behaviours. The heterogeneity of the methods necessary to determine these behaviours reveals both the complexity of the behaviours themselves (Steg, Bolderdijk, Keizer, \& Perlaviciute, 2014) and the need to employ a theory that can sufficiently model their complexity (de Leeuw, Valois, Ajzen, \& Schmidt, 2015). Only a few studies have included demographic variables to determine a predictive model for these eco-friendly behaviours (de Leeuw et al., 2015;), even though they are key determinants. One study found that demographic variables contributed to the complexity of the eco-friendly behaviours model (Olya \& Gavilyan, 2017). Prior research has also shown that personality traits play a vital role in influencing customers' decision-making processes (Tang \& Lam, 2017). Moghavvemi, Woosnam, Paramanathan, Musa, \& Hamzah (2017) recommended that hospitality and tourism scholars should pay attention to personality, as different traits may result in consumers feeling different levels of responsibility for pro-environmental behaviours. To sufficiently examine the heterogeneity in predicting WLP in the travel industry, and to develop a conceptual WLP model, this study employs complexity theory, which is recommended for modelling complex social phenomena (Olya \& Akhshik, 2019; Woodside, 2016; Olya et al., 2019). The results of the model testing are supported by the tenets of this theory.

\section{Willingness to pay more for green travel products}

Green travel products are often priced more highly than others, owing to customers' general willingness to pay more for eco-friendly products (e.g. Tang \& Lam, 2017; Rahman \& Reynolds, 2016). Lee, Bhatt, \& Suri (2018) found that $78 \%$ of the participants in their study 
were willing to pay a premium price for green products. For the present paper, we conducted a pilot study on this question. A sample of consumers $(n=60)$, when asked if they were prepared to pay more for green travel products, replied that they were. Specifically, the pilot study indicated that the consumers were willing to pay an additional $25-35 \%$ for these products.

Prior research has pointed out that the factors affecting customers' willingness to pay more for green products are still unknown (Tully \& Winer, 2014). Some managers believe consumers are unwilling to pay extra for inconvenient green initiatives and practices, while some consumers think green products are expensive and of low quality (Tang \& Lam, 2017). Consumer demand for green products is low (Lin \& Huang, 2012). While some consumers are unwilling to pay a premium price (Manaktola \& Jauhari, 2007), others tend to pay more, regardless of the obvious inconvenience (Tang \& Lam, 2017). Bohdanowicz (2006) argued that environmental concerns were not the main issue for UK hotel managers. A number of hospitality and tourism researchers have explored the issue (Han et al., 2010; Radwan, Jones, \& Minoli, 2012). Some (e.g. Tang and Lam, 2017) have called for more research on guests' decision-making in choosing to pay more for a green hotel. Therefore, the present study investigates the factors affecting travellers' willingness to pay more for green travel products.

\section{Research model}

Complexity theory is employed in the present research to aid the development of the proposed framework, which is conceptualised by integrating the predictors of TPB and TCV with VBN theory in order to describe travellers' willingness to pay more for eco-friendly travel products. Several authors have used this approach to assess pro-environmental behaviours (Goh et al., 2017; Han, 2015; Han et al., 2017). TPB is based on the tenet that behaviour is mainly predicted by intentions, which is also predicted by attitudes, subjective norms and perceived behavioural 
control (PBC) (Ajzen, 1991). On the other hand, TCV - a multidimensional approach developed by Sheth et al. (1991) - asserts that customer behaviour is influenced by five consumption values: social, epistemic, functional, conditional and emotional. Gonçalves et al. (2016) found that consumption values were significant in explaining green buying behaviour. Finally, VBN theory has been conceptualised from the value theory, norm activation model and the new environmental paradigm (Stern et al., 1999). It posits that the sequential determinants of pro-environmental behaviours are a result of the influence of the values of the new environmental paradigm, which in turn affects one's personal norms (Han et al., 2017).

Determining the interacting factors of WLP indicators and behavioural outcomes is a complex challenge, but complexity theory is well placed to explain the heterogeneity and asymmetric relationships between predictors and any related outcome(s) (Baggio, 2008). Although there is no clear definition of this theory (Johnson, 2007), it is based on systems theory, which uses a blend of conceptual frameworks to develop models and analyse complex systems. The system is said to be complex because it allows outcomes from several parts that are interrelated and interconnected. Each part of this complex system can be considered as a system on its own, and every single system has the tendency to be a larger complex system (Ackoff \& Emery, 2005). Several disciplines such as socioeconomics, health and politics have used this theory to shed light on dynamic processes. This is mainly because concepts like simple linear equilibrium do not fully explain the associations of "black-box" configurations, a situation which is compounded by the multiple interactions of the components (Antimova, Nawijn, \& Peeters, 2012; Olya et al., 2019).

With regard to the complexity of pro-environmental behaviours and willingness to pay more, the key tenets of complexity theory were used to construct and evaluate the suggested configurational model (Olya et al., 2019; Krajhanzl, 2010). Predictive configurations were labelled and classified as beliefs, values, attitudes and norms (Olya et al., 2019). As 
demonstrated in Figure 1, demographic variables, personality traits, VBN theory, TCV and TPB were combined and demonstrated as configurations for stimulating WLP.

Arrow A in Figure 1 indicates a combination of demographic factors (gender, age, marital status, ethnicity, education level and income) that represent causal models for predicting high and low WLP. Seven value variables were combined to describe an algorithm for stimulating WLP, represented by Arrow B1 [WLP = f (alt, ego, bio, sov, emv, cov, epv)]. The demographic and value variables were combined and indicated by Arrow B2, and explore causal recipes to predict WLP scores. As represented by Arrow C1, three drivers (dsn, mrn, ijn) of normative influence were configured as antecedents of the causal models for predicting WLP. The combination of demographic and value variables and normative influence is indicated by Arrow C2 and suggests causal models for predicting high and low WLP scores. Arrow D1 in Figure 1 represents causal recipes for stimulating WLP. Personality traits and beliefs suggest causal models to predict WLP. Demographic and value variables, normative influence, personality traits and beliefs were integrated to examine causal recipes for stimulating high WLP levels, represented by Arrow D2. The fsQCA findings are shown in Table A2.

\section{Methodology}

This study used a mixed-method approach in which the qualitative research phase was extended by two quantitative techniques of data gathering and analysis (Tashakkori \& Teddlie, 2003; So, Oh, \& Min, 2018). Mixed-method research helps to corroborate the findings of both qualitative and quantitative analyses (Pham, Tučková, \& Jabbour, 2019; So et al., 2018), providing better findings (Tashakkori \& Teddlie, 2003; Tashakkori \& Creswell, 2007) with enhanced reliability and validity (Bryman \& Bell, 2011). The present study therefore used a mixed-method approach, firstly because of the contradictory and inconclusive findings of 
previous research on the factors affecting consumers' willingness to pay more for green products, and secondly because of the need to contextualise this analysis in the travel context. The qualitative technique was used first, to complement the incomplete and inconsistent findings of prior studies, followed by the quantitative approach to test the study hypotheses.

\section{The qualitative phase and its results}

Eight semi-structured focus groups, held in February 2018, were used to gather qualitative information, with the aim of better understanding the factors affecting customers' willingness to pay more for green travel products, the paucity of qualitative enquiries on the subject, and the incomplete or contradictory results of prior studies. Six of the groups comprised members who had bought green travel products in the past, while the members of the other two had no history of such purchases. All the participants were asked to read carefully the description of a green travel product before attending to ensure they all had an equal awareness of the details. In addition, in-depth interviews in London (each lasting 30-45 minutes) were held over a fiveday period in February 2018. All the interviews were recorded with consent, and the researcher took notes while conducting them.

The participants were asked to talk about their experiences and knowledge of green travel products, the key factors affecting their attitudes to them, and their willingness to pay for them. The researcher also asked general questions about their experiences (e.g. their impressions, likes, dislikes and fulfilment of their expectations), and specific questions about issues such as their values, attitudes, moral norms, personality traits and subjective norms. The participants were asked to circle any words in the questions they found ambiguous and/or confusing, and to provide any general comments on the statements. 
The data was analysed and themes were derived according to the researcher's understanding of the subject matter and the meaning captured in the content (So et al., 2018; Ryan \& Bernard, 2003). Two of the researcher's colleagues independently verified the accuracy of the list of factors that had been identified. The results of the analysis demonstrated that the variables identified in prior studies - such as moral norms, egoistic, biospheric, altruistic, conditional and social values, PBC, awareness of consequences and attitude - appeared to drive travellers' willingness to pay for green travel products; while injunctive norms, agreeableness, extraversion and environmental beliefs, which had not been examined in previous studies, were found to be essential to the willingness to pay. The qualitative results and the findings of the prior studies were incorporated into an integrated model of the factors affecting travellers' willingness to pay more for green travel products, as shown in Figure. 1.

\section{Insert Figure 1 about here}

\section{Quantitative method}

\section{Study 1}

The data was collected from 20 February 2018 to 5 March 2018 using a questionnaire, and was used to validate the model. The study population was every tourist who had bought a green travel product in the last six months.

Following clearance by the human ethics review committee of the researcher's university, the e-mail addresses of 2,000 prospective respondents were bought from a reputable UK marketing list company with access to a representative panel of more than 3.5 million registered travellers. A hyperlink was sent to a random sample of 2,000 of them. A filtering question at the beginning of the questionnaire, asking respondents if they had bought green travel products in the past six months, determined the constituents of the study sample. The e-mail invitation also set out the purpose of the study, the time it would probably take to complete the survey, and a hyperlink 
to the URL of the questionnaire. The data collection lasted for approximately two weeks. In total, 683 participants were approached. Forty-one responses with missing values were excluded; 642 replies were therefore considered valid for further analysis. Of the remaining group of respondents, $58 \%$ were male, $41 \%$ were aged between 36 and 54, and $46 \%$ had bought green travel products between one and three times in the last six months. The stated income of the largest group of participants (39\%) was between $£ 25,001$ and 50,000 , and $46 \%$ of the total had a university degree. The respondents gave their ethnicity as white (46.2\%), hispanic (19.8\%), Asian (15.5\%), African/black (11.5\%) or other (7.0\%).

\section{Measurement instruments}

Scales which had been validated in the literature were used to ensure the validity and reliability of the study measurements. Measures of willingness to pay more were borrowed from prior studies (e.g., Wei, Ang, \& Jancenelle, 2018; Han et al., 2010). The scales in four of the items, as suggested by previous studies (e.g. Dunlap, Van Liere, Mertig, \& Jones, 2000; Kazeminia, Hultman, \& Mostaghel, 2016), were adapted to measure the variable of environmental beliefs. Attitude was measured using five items from Han et al. (2017) and Line and Hanks (2016). Perceived behavioural control was operationalised with three items, as proposed by Ajzen (1991; 2011) and Han and Kim (2010). Awareness of consequences was adopted from Han et al. (2016). Established and validated measures for injunctive norm, descriptive norm and personal moral norm were adopted from previous studies (e.g. Chen \& Peng, 2012; Arvola et al., 2008; Steg \& De Groot, 2010; Han et al., 2010; Fornara et al., 2016). The value variables (i.e. egoistic, biospheric, altruistic, social, emotional, conditional and epistemic) were borrowed from prior studies (e.g. Lin \& Huang, 2012; Gonçalves et al., 2016). Finally, 
personality traits (e.g. extraversion and agreeableness) were drawn from Judge, Heller, and Mount (2002).

All the items were measured on a five-point Likert scale ranging from 5 (strongly agree) to 1 (strongly disagree). Ten academic experts in tourism and hospitality confirmed the content validity of the measures. The variables were then further tested through personal interviews with 50 customers in London who had already bought green travel products, to ensure that the wording of the questionnaire was clear, and to evaluate the quality of the content and the reliability of the measures.

Common method bias was recognised as a potential issue in this study, so this was assessed in three different ways (Podsakoff \& Organ, 1986). Harman's single-factor test indicated that the largest factor accounted for $22.46 \%$ (the variances explained ranged from $17.28 \%$ to $22.46 \%$ ) and no general factor accounted for more than $50 \%$ of the variance (Teo et al., 2015). The general factor covariate method was then used to assess potential method effects. The findings showed that the re-estimated framework with the common method variance factor demonstrated insignificant framework enhancement compared with the original. Finallly, Lindell and Whitney's (2001) marker variable method was used: all the coefficients remained significant after the marker variable was controlled for. The results of these three methods therefore confirmed that common method bias was not a serious concern.

Close attention was also paid to the design and administration of the questionnaire: the questions were mixed and different types of scale used to ensure the participants could not combine related items. An evaluation using an approach from Malhotra, Kim, and Patil (2006) revealed negligible common method variance and no common method bias. 


\section{Analysis and results}

The data was analysed using SPSS, AMOS and fsQCA software (Ragin, Drass, \& Davey, 2006; Olya et al., 2019). After the assessment of the measurement model, cross-tabulation analyses were conducted to indicate any occurrence of contrarian cases. Previous studies on green products have demonstrated a high cause-effect interdependence between factors. The use of fsQCA avoids issues that arise from the use of regression analysis (Woodside, 2013). Previous research has also paid considerable attention to fsQCA in various fields, because when it is applied together with SEM, the combination provides a deeper and richer perspective on the data (Wu et al., 2014; Woodside, 2014; Leischnig \& Kasper-Brauer, 2015; Pappas, Kourouthanassis, Giannakos, \& Chrissikopoulos, 2016). Considerable attention has been paid to the application of fsQCA in the travel and tourism context (e.g. Pappas \& Papatheodorou, 2017; Olya \& Gavilyan, 2017; Olya, Khaksar, \& Alipour 2017; Olya et al., 2019; Olya \& AlAnsi 2018; Pappas \& Papatheodorou, 2017). The key tenets of complexity theory were used to assess the fsQCA results (Olya et al., 2019; Woodside, 2014). Lastly, we assessed the predictive validity of the study mode (Olya, Altinay, \& De Vita, 2018; Olya et al., 2019). Skewness and kurtosis tests indicated no departure from normality in the measurement items (George \& Mallery, 2010). A Bartlett test of sphericity (4146.441) and KMO measure (0.889) of sampling adequacy indicated a significant association between the factors to guarantee the factor analysis application (Hair, Hult, Ringle, \& Sarstedt, 2015).

\section{Measurement model}

Both the reliability and validity of the measurement model were evaluated (Hair et al., 2015). The confirmatory factor analysis results showed that all the items had significant influence on their specified variables $(\mathrm{p}<0.001)$, and loaded above 0.70 on their constructs (Hair et al., 
2015). Convergent validity was evaluated using composite reliability, average variance extracted (AVE) and Cronbach's alpha. All the results (set out in Table 1) indicated satisfactory convergent validity. The loadings of all the variables were above the recommended threshold of 0.7 proposed by Hair et al. (2015) and Bagozzi and Yi (1988). The AVE value for each construct ranged from 0.5014 to 0.720 , exceeding the recommended value of 0.50 suggested by Fornell and Larcker (1981) and Hair et al. (2015). The Bentler-Bonnet coefficient was 0.941, which is also indicative of adequate convergent validity. Moreover, the AVE square root for all factors was always higher than its correlation with any other factor, supporting the discriminant validity of the research variables (Klarner, Sarstedt, Hoeck, \& Ringle, 2013) (Table 2). The Cronbach's alpha values seem to have ranged from 0.872 to 0.931 . In addition, building on Bagozzi et al. (1991) to address the multi-collinearity issue, all the variance inflation factors were below 3, suggesting that collinearity issues were absent.

\section{Insert Tables 1 and 2 about here}

\section{Cross-tabulation analysis}

The results of the cross-tabulation analysis indicated asymmetric links between WLP and its drivers. Table 3 shows two examples of heterogeneity in specifying WLP. For example, 170 travellers (26\%) who were only minimally concerned with egoistic values, and 120 (19\%) who were neutral on these values, had a high level of WLP (as shown in Table 3A). These findings are consistent with the results of Olya et al. (2019) and Steg et al. (2014), who found that egoistic values had either no significant influence, or a negative influence, on proenvironmental behaviours. 
The relationship between PBC and WLP represents another example of the occurrence of contrarian cases. Table 3B shows the findings of Cramér's V and cross-tabulation analyses. A total of 118 travellers (19\%) who indicated low PBC, and 128 (20\%) who were undecided regarding PBC, were willing to pay more for green travel products. These results are consistent with prior research findings (e.g. Olya et al., 2019; Goh et al., 2017), which found that PBC had no significant influence on pro-environmental behaviours. The Cramér's V test results indicated a significant medium effect size for egoistic values and PBC (Cohen, 1977). Regarding the heterogeneity problems in predicting WLP, Olya et al. (2019) found that attitude had no significant effect on pro-environmental behaviours. These results confirm that conceptual frameworks for stimulating pro-environmental behaviours should be conducted using asymmetric rather than symmetric methods. The occurrence of heterogeneity is explained by the fsQCA results in the next section.

\section{Insert Table 3 about here}

\section{FsQCA results}

Tables 4 and 5 present the fsQCA results, demonstrated by Arrows A-D2. The function of fsQCA, according to the Quine-McCluskey method, is to calculate causal recipes that enable the prediction of conditions that result in high and low WLP. Regarding Arrow A, Table 4 shows that using demographics as indicators [A: wlp $=f$ (ag, eth, inc, edu, gen, mrs)], produces two causal recipes, M1 and M2, that result in high WLP scores (coverage $=0.793$, consistency $=0.971) . \mathrm{M} 1$ indicates that high WLP is attained when travellers are female, older, highly educated and married, and have a low income; while M2 ( gen*edu*inc*mrs), shows high WLP among male, highly educated, married educators with a high income level. Unlike traditional approaches that offer a single causal recipe for predicting WLP, this innovative 
method provides one or more casual recipes for predicting it. Traditional approaches also show low WLP scores in cases that represent the mirror opposite of the causal recipes for high WLP. However, the findings shown in Table 4 indicate that the conditions for WLP negation $(\sim \mathrm{A}$ : M1. gen* ed* $^{*}$ inc*mrs) is not a mirror opposite of the algorithms resulting in high WLP scores (Table 4, A: M1 and M2).

Insert Tables 4 and 5 about here

Regarding the configuration of values, the fsQCA results indicate that travellers with high biospheric, altruistic, social, emotional, conditional and epistemic values have a high degree of WLP (Table 4, B1: M1. ego*bio*alt*sov*emv*cov*epv). Based on (M2. bio*sov*cov), travellers with high levels of biospheric, social and conditional values show a high level of WLP. These results are consistent with Gonçalves et al. (2016), and indicate that biospheric, altruistic, social, emotional, conditional and epistemic values have significant effects on WLP (Table 4, B1: M1. ego*bio*alt*sov*emv*cov*epv). For the normative influence configuration $(\mathrm{C} 1)$, the results indicate that two models lead to high WLP (coverage $=0.963$, consistency $=0.978)$. M1 shows that a combination of personal moral norms, injunctive norms and descriptive norms leads to high WLP; while in M2, travellers with higher personal moral and descriptive norms had high WLP. In contrast, a model with a low level of descriptive norms (Table 4, C1: M1. dsn) leads to WLP negation.

Arrow B2 indicates a combination of demographics and values configurations, and offers four causal recipes for achieving high WLP. For instance, M1 indicates high WLP attained when travellers are older, female, white, highly educated, married, and have a high income, low egoistic values, and high degrees of biospheric, social, altruistic, emotional, conditional and epistemic $\quad$ values $\quad$ (Table $5, \quad$ M1. ag*eth* inc*edu*gen*mrs* ego * bio alt*sov*emv*cov*epv). The three other causal recipes for attaining high WLP and 
two causal algorithms predicting WLP negation are demonstrated by B2 and $\sim$ B2 respectively (as shown in Table 5).

A combination of demographic factors, values and normative influence are demonstrated by $\mathrm{C} 2$. The fsQCA results show five causal recipes leading to high WLP (coverage $=0.583$, consistency $=0.998)$. For example, M1 reveals that older, white, low income, educated, married females with a high level of low egoistic values, and high degrees of biospheric, social, altruistic, emotional, conditional and epistemic values, and of moral, descriptive and injunctive

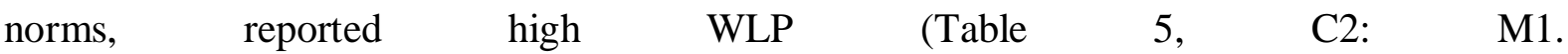
ag*eth inc*edu*gen*mrs* ego*bio alt*sov*emv*cov*epv*mrn*inj*dsn). Using a combination of demographic factors, values and normative influence, two causal configurations were examined for WLP negation (coverage $=0.402$, consistency $=0.563$ ).

The results of the fsQCA also indicate that a combination of demographics, values, normative influence, beliefs and personality traits (Arrow D2) reported eight causal recipes lead to high WLP. for instance, M1 indicates older educators who are white, low income, married, female, low egoistic values, high degree of biospheric, social, altruistic, emotional, conditional, epistemic value, moral norm, descriptive, injunctive norm, positive attitude, high level of awareness of consequences, environmental beliefs, agreeableness and extraversion lead to $\begin{array}{llllll}\text { higher } & \text { WLP } & \text { (Table } & 5, & \text { D2: } & \text { M1. }\end{array}$ ag*eth inc*edu*gen*mrs* ego*bio alt*sov*emv*cov*epv*mrn*inj*dsn*agr*att*ext*awr* pbc*enb). These factors also reveal three causal algorithms for WLP negation (coverage = 0.527 , consistency $=0.743$ ). The findings indicate that the complexity and heterogeneity of the associations of INT drivers can be examined by complexity theory. Based on complexity theory, a combination of the drivers indicates the causal recipes leading to outcomes (e.g. WLP), and the role of each driver relies on the attributes of other the indicators in a causal model. 


\section{Predictive validity}

Table 6 presents evidence of the predictive validity. The research sample was divided into two subsamples and testing models that emerged from subsample 1 using subsample 2 (Olya et al., 2019; Wu et al. 2014). The fuzzy XY plots for two models are described, indicating the asymmetric between WLP and its causal recipes. Subsample 2 was used to test these two causal models (M1 and M2), and the results showed that both had high levels of consistency and coverage that confirmed their predictive validity (e.g. Woodside, 2016).

\section{Insert Figure 2 about here}

Figure 2 shows that the consistency of the model 1 test in subsample 2 was 0.863 . Thus, the models have high predictive capacity (Alonso-Dos-Santos \& Llanos-Contreras, 2018). As suggested by several prior studies (e.g. Hsiao et al., 2018; Olya et al., 2019; Wu et al., 2014), the predictive validity of the suggested model's use of another sample is significant.

\section{Insert Table 6 about here}

\section{Complexity theory evaluation}

Key tenets of complexity theory were used to evaluate the fsQCA results shown in Table 6. The findings supported Tenet 1, i.e. that it is rare for a single driver to stimulate high/low WLP. Instead, a combination of drivers creates the conditions resulting in high/low WLP (Tenet 2). Based on the fsQCA results, descriptive norms, as a single predictor, are insufficient to lead to high WLP, but combining them with personal moral norms and injunctive norms can do so (Table 4, C1: M1. mrn *inj*dsn). While the symmetric approach provides one model, 
complexity theory with fsQCA demonstrates that one or more causal models (Tenet 3) can attain high/low WLP. Table 4 (D2) indicates that there are eight alternative models for achieving high WLP.

As noted above, in traditional approaches, causal recipes for the negation of WLP are mirror inversions of models resulting in high WLP. Complexity theory supposes that causal models for WLP negation are unique, and are not simply inversions of the models for high WLP (Tenet 4). For instance, eight causal recipes lead to high WLP (Table 4, B2), while the three causal models resulting in low WLP are not a mirror inversion of any of them (Table $4, \sim \mathrm{B} 2$ ). The fsQCA findings therefore support Tenet 5. Table 7 demonstrates that the coverage value for the cases with high WLP is lower than 1.00. Thus, these results support Tenet 6 (Woodside, 2014; Olya et al., 2019).

Overall, the findings reveal that WLP should be modelled using complexity theory and fsQCA due to the ingrained complexity of WLP and the associations of a large number of drivers.

\section{Insert Table 7 about here}

\section{Study 2}

The second phase of the data collection was implemented six months after the first study. The authors used a telephone survey to assess travellers' behaviour. The main aim of Study 2 was to examine the link between travellers' willingness to pay for green travel products and their actual behaviour. The participants were reminded of their preferred green travel products as mentioned in the first stage of the survey, and were asked how many times in the past six months they had purchased them. Their actual behaviour was inferred from the number of items they had bought in the six months between the initial web-based survey of Study 1 and the follow-up telephone survey of Study 2. 
All 642 travellers who had taken part in the first study were approached again. A total of 438 replies were considered valid for further analysis. Of these participants, 53\% were male, 37\% were aged between 36 and 54, and 32\% stated that they had bought green travel products between one and three times in the past six months. The stated income of the largest group of participants (37\%) was from $£ 25,001$ to 50,000 , and $41 \%$ of the total had a university degree. The respondents indicated their ethnic groups as follows: white $(41.2 \%)$, hispanic $(21.8 \%)$, Asian (17.5\%), African/black (14.5\%) and other (5.0\%).

Correlation analysis was used to assess the proposed relationship between the travellers' willingness to pay and their actual behaviour, because the actual behaviour was captured using single-item metric scales. The link was found to be positive and significant $(\mathrm{p}<0.01)$, a result that further augments the evidence of a strong relationship between travellers' willingness to pay more for green travel products and their actual behaviour.

\section{Robustness checks}

The robustness of our findings was checked using two additional analyses. The findings were validated by investigating the link between travellers' willingness to pay and actual behaviour using three-month $(n=472)$ and six-month $(n=519)$ time lags between the second study survey and the current one.

Correlation analysis was performed to assess the proposed relationship between willingness to pay and actual behaviour. Specifically, the positive and significant main effect of travellers' willingness to pay more on actual behaviour $(\mathrm{p}<0.01)$ was replicated. Additionally, an analysis of variance (ANOVA) was run to validate the findings regarding the link between willingness to pay and actual behaviour for the different time frames. The outcomes of these additional tests mimicked the findings of the main model, indicating the robustness of the findings. 


\section{Conclusion and implications}

Overall, our study makes significant contributions to the travel and tourism literature both methodologically and theoretically, in particular through the innovative application of a new statistical technique (fsQCA) and complexity theory. As a result, we have shown how a complex combination of demographic factors, values, normative influence, personality traits and beliefs function as a causally sufficient configuration of travellers' willingness to pay more for green travel products. Eight causal recipes emerged from our research, with the results suggesting that predictors like egoistic values can serve as positive and negative indicators of WLP, and that causal conditions for WLP exist when travellers have low PBC and egoistic values. Our findings can inform policies and decisions in numerous ways, including by helping to provide restrictive conditions in line with the WLP negation models.

\section{Methodological contributions}

By using fsQCA as a theoretical approach to modelling WLP, our study contributes strongly to methodological advancement. This approach allows asymmetric modelling by exploring the causal conditions for high and low WLP. The complex interplay between different factors, which we have demonstrated using this distinctive approach, highlights that a simple tactical plan is not appropriate, and a truly actionable environmental plan will need to recognise the sophistication of an individual's behavioural intentions. Most prior studies using TPB have focused only on the net effect of TPB indicators in predicting these behaviours.

For the first time we have shown the importance of combined factors such as personality traits like extraversion and agreeableness and of subjective and personal moral norms, as well as demonstrating that behaviour is influenced by the ability to act confidently. In the eight causal 
recipes for high WLP identified in our findings, a simple driver (i.e. values) was important in all, but only a combination of multiple factors was sufficient to achieve high WLP. We have therefore shown the advantages of fsQCA over the regression-based approach, demonstrating the suitability of survey data for use in a large N QCA, showing more recent robustness tests, and demonstrating the use of customers' socio-demographic variables as a pathway to WLP for a closer "case orientation". The fsQCA results also support the tenets of complexity theory.

\section{Theoretical contributions}

Among a number of theoretical contributions, the study has used TCV to understand willingness to pay for green travel products. The findings not only help to identify the consumer role in consumption values, but also the interrelationship with willingness to pay more, providing different justifications for WLP according to the existence of alternative paths to the outcome, and demonstrating that the consumption values or their combinations that explain WLP are not necessarily the same for WLP.

The ability to explore more than one causal condition as a consequence of variations in the interactions of several configurations, has enabled WLP to be addressed despite its sophistication. The findings suggest a need to alter present conditions to realise high behavioural outcomes. The use of fsQCA enabled the identification of eight causal models leading to high WLP (as shown in Table 5), providing practitioners with guidance on how to attain this outcome. In particular, the combined use of fsQCA and complexity theory - an approach about which little was previously known - allowed for the inclusion of demographic indicators for predicting WLP. The results from the models with demographic indicators can be used to target specific markets based on travellers' education and income level, age, ethnicity, marital status and gender (see Table 4, A). 
Our study therefore builds on existing research which has relied on TPB, TCV and VBN to model WLP, despite their insufficiency to effectively predict it. This study combines and expanding these theories to support the proposed conceptual model. The use of complexity theory allows adequate explanation of the complex combinations of the predictors of TPB, TCV and VBN, which may have non-linear relationships; and also allows for the evaluation of contradictions in the causal configurations. Furthermore, the study has assimilated intentional and behavioural data in a context of repeated interactions between travellers and travel companies, enabling greater confidence in the results since behavioural disposition is predicted by an aggregation of behaviours rather than by a single behaviour (Ajzen, 1991).

The findings of the cross-tabulations test also demonstrated that the heterogeneity issues encountered in modelling WLP can be explained by complexity theory.

\section{Managerial contributions}

Our results provide managers with many practical ways to target their green tourism products more effectively. For example, our findings reveal that personality traits play a key role in willingness to pay more for green travel products, with agreeableness and extraversion indicated as the most influential determinants. Agreeable consumers are more likely than others to show a caring attitude, to be socially concerned or engaged in green issues, and to hold positive attitudes to green products, and are therefore more likely to choose green travel products. These findings are consistent with prior studies (e.g. Milfont \& Sibley, 2012; Brick \& Lewis, 2016; Tang \& Lam, 2017). Our results also show that extraversion has a positive and significant effect on WLP, which is consistent with the results of previous research on green consumption (e.g. Brick \& Lewis, 2016; Tang \& Lam, 2017). Marketing campaigns could therefore stress the characteristics of extraversion (e.g. sociability, outgoingness, 
expressiveness, novelty-seeking and positive energy towards others), and/or of agreeableness (i.e. compassion, sympathy, generosity, cooperation and altruism).

Since the results also indicate the key role of personal moral norms, managers could use advertising campaigns to imprint on customers' minds that it is morally wrong to buy travel products that damage the environment. Other useful strategies could include cards placed in guest rooms with a message about a moral norm (e.g. saving energy and reusing towels is the right thing to do). As subjective norms also emerged as important determinants of willingness to pay more, managers could use word-of-mouth marketing strategies as an effective response.

Given another significant finding, that behaviour is influenced by the ability to act confidently, travellers' perceptions and normative beliefs could be influenced by programmes designed to develop their confidence and engage them in sustainability events. Managerial responses could include training programmes on developing pro-environmental behaviours, social media posts on environmental impacts, or campaigns encouraging young people to conserve endangered species. To maximise travellers' pro-environmental behaviours and WLP, communities could develop normative messages that promote conservation of the environment by travellers.

Marketing managers can also enhance consumer acquisition strategies such as segmenting customers according to combinations of their values, and develop appropriate product offerings, such as material printed on recycled material that provides carbon footprint information.

\section{Limitations and future research avenues}

Our study is not without caveats. We tested only one outcome (WLP). However, our theoretical and analytical techniques have the potential to measure other conditions and outcomes. Further research should therefore investigate outcomes separately from intentions, for example the 
long-term effects of pro-environmental behaviours and the intention-behaviour gap. Future research could examine green products beyond the travel industry, while a larger sample size would ensure generalisability. More configurations could be added to the model we employed, and further research on WLP could evaluate the tipping point concept. Comparative analysis should be undertaken to tests pro-environmental behaviours and willingness to pay spillover effects against the complexity of other behaviours. Such studies, using different conditions and settings, could expand our understanding of pro-environmental behaviours. Finally, while our study has focused on the demand perspective, future supply-orientated studies could assess how policymakers and travel firms could influence ethical views of green products, including eco-friendly travel. 


\section{References}

Ackoff, R. L., \& Emery, F. E. (2005). On purposeful systems: An interdisciplinary analysis of individual and social behavior as a system of purposeful events. New York: Transaction.

Ajzen, I. (1985). From intentions to actions: A theory of planned behavior. In Action control (pp. 11-39). Berlin, Heidelberg: Springer.

Ajzen, I. (1991). The theory of planned behavior. Organizational Behavior and Human Decision Processes, 50(2), 179-211.

Ajzen, I. (2011). The theory of planned behaviour. Reactions and Reflections, 26(11), 23-48.

Akhtar, P., Khan, Z., Frynas, J.G., Tse, Y.K., \& Rao-Nicholson, R. (2018). Essential microfoundations for contemporary business operations: Top management tangible competencies, relationship-based business networks and environmental sustainability. British Journal of Management, 29(1), 43-62.

Antimova, R., Nawijn, J., \& Peeters, P. (2012). The awareness/ attitude-gap in sustainable tourism: A theoretical perspective. Tourism Review, 67(3), 7-16.

Arvola, A., Vassallo, M., Dean, M., Lampila, P., Saba, A., Lähteenmäki, L., \& Shepherd, R. (2008). Predicting intentions to purchase organic food: The role of affective and moral attitudes in the Theory of Planned Behaviour. Appetite, 50(2-3), 443-454.

Baggio, R. (2008). Symptoms of complexity in a tourism system. Tourism Analysis, 13(1), 120.

Bagozzi, R. P., \& Yi, Y. (1988). On the evaluation of structural equation models. Journal of the Academy of Marketing Science, 16(1), 74-94.

Bohdanowicz, P. (2006). Environmental awareness and initiatives in the Swedish and Polish hotel industries - Survey results. International Journal of Hospitality Management, 25(4), 662-682.

Brach, S., Walsh, G., \& Shaw, D. (2018). Sustainable consumption and third-party certification labels: Consumers' perceptions and reactions. European Management Journal, 36(2), 254-265.

Brick, C., \& Lewis G.J. (2016). Unearthing the "green" personality: Core traits predict environmentally friendly behaviour. Environ Behav, 48(5), 635-658.

Bryman, A., \& Bell, E. (2011). Business research methods (3rd ed.). Oxford: Oxford University Press.

Buhalis, D., \& Leung, R. (2018). Smart hospitality - Interconnectivity and interoperability towards an ecosystem. International Journal of Hospitality Management, 71(3), 41-50.

Chen, A., \& Peng, N. (2012). Green hotel knowledge and tourists' staying behavior. Annals of Tourism Research, 39(4), 2211-2219.

Cohen, J. (1977). Statistical power analysis for the behavioral sciences (rev. ed.). New York: Academic Press. 
De Leeuw, A., Valois, P., Ajzen, I., \& Schmidt, P. (2015). Using the theory of planned behavior to identify key beliefs underlying pro-environmental behavior in high-school students: Implications for educational interventions. Journal of Environmental Psychology, 42(2), 128-38.

Do Paço, A., Shiel, C., \& Alves, H. (2019). A new model for testing green consumer behaviour. Journal of Cleaner Production, 207(4), 998-1006.

Dolnicar, S., Knezevic Cvelbar, L., \& Grün, B. (2017). Do pro-environmental appeals trigger pro-environmental behavior in hotel guests? Journal of Travel Research, 56(8), 988997.

Eustice, C., McCole, D., \& Rutty, M. (2019). The impact of different product messages on wine tourists' willingness to pay: A non-hypothetical experiment. Tourism Management, 72, 242-248.

Fornara, F., Pattitoni, P., Mura, M., \& Strazzera, E. (2016). Predicting intention to improve household energy efficiency: The role of value-belief-norm theory, normative and informational influence, and specific attitude. Journal of Environmental Psychology, $45,1-10$.

Gao, Y. L., \& Mattila, A. S. (2016). The impact of option popularity, social inclusion/exclusion, and self-affirmation on consumers' propensity to choose green hotels. Journal of Business Ethics, 136(3), 575-585.

George, D., \& Mallery, M. (2010). SPSS for window step by step: A simple guide and reference (10th ed.). Boston, MA: Pearson.

Gil-Soto, E., Armas-Cruz, Y., Morini-Marrero, S., \& Ramos-Henríquez, J. M. (2019). Hotel guests' perceptions of environmental friendly practices in social media. International Journal of Hospitality Management, 78(2), 59-67.

Goh, E., Ritchie, B., \& Wang, J. (2017). Non-compliance in national parks: An extension of the theory of planned behaviour model with pro-environmental values. Tourism Management, 59(4), 123-127.

Gonçalves, H.M., Lourenço, T.F., \& Silva, G.M. (2016). Green buying behavior and the theory of consumption values: A fuzzy-set approach. Journal of Business Research, 69(4), 1484-1491.

Gupta, A., Dash, S., \& Mishra, A. (2019). All that glitters is not green: Creating trustworthy ecofriendly services at green hotels. Tourism Management, 70(4), 155-169.

Hair, J. F., Hult, G. T. M., Ringle, C., \& Sarstedt, M. (2015). A primer on partial least squares structural equation modeling (PLS-SEM) (2nd ed.). Thousand Oaks, CA: Sage.

Han, H. (2015). Travellers' pro-environmental behavior in a green lodging context: Converging value-belief-norm theory and the theory of planned behavior. Tourism Management, 47, 164-77.

Han, H., \& Kim, Y. (2010). An investigation of green hotel customers' decision formation: Developing an extended model of the theory of planned behavior. International Journal of Hospitality Management, 29(4), 659-668. 
Han, H., Hsu, L. T. J., \& Sheu, C. (2010). Application of the theory of planned behavior to green hotel choice: Testing the effect of environmental friendly activities. Tourism Management, 31(3), 325-334.

Han, H., Meng, B., \& Kim, W. (2017). Emerging bicycle tourism and the theory of planned behavior. Journal of Sustainable Tourism, 25(2), 292-309.

Herrero, L. C., Sanz, J.Á., Bedate, A., \& Barrio, M. J. (2012). Who pays more for a cultural festival, tourists or locals? A certainty analysis of a contingent valuation application. International Journal of Tourism Research, 14(5), 495-512.

Hsiao, T. Y., Chuang, C. M., \& Huang, L. (2018). The contents, determinants, and strategic procedure for implementing suitable green activities in star hotels. International Journal of Hospitality Management, 69(3), 1-13.

Joanes, T., Gwozdz, W. and Klöckner, C.A., 2020. Reducing personal clothing consumption: A cross-cultural validation of the comprehensive action determination model. Journal of Environmental Psychology, 23(7)101-396.

Johnson, N. F. (2007). Two's company, three is complexity: A simple guide to the science of all sciences. London: Oneworld.

Judge, T. A.,Heller, D., \& Mount, M. K. (2002). Five-factor model of personality and job satisfaction: A meta-analysis. Journal of Applied Psychology, 87(3), 530-541.

Kang, K. H., Stein, L., Heo, C. Y., \& Lee, S. (2012). Consumers' willingness to pay for green initiatives of the hotel industry. International Journal of Hospitality Management, $31(2), 564-572$.

Kazeminia, A., Hultman, M., \& Mostaghel, R. (2016). Why pay more for sustainable services? The case of ecotourism. Journal of Business Research, 69(11), 4992-4997.

Kiatkawsin, K., \& Han, H. (2017). Young travelers' intention to behave pro-environmentally: Merging the value-belief-norm theory and the expectancy theory. Tourism Management, 59(1),76-88.

Kim, Y., \& Han, H. (2010). Intention to pay conventional-hotel prices at a green hotel - A modification of the theory of planned behavior. Journal of Sustainable Tourism, 18(8), 997-1014.

Klarner, P., Sarstedt, M., Hoeck, M., \& Ringle, C. M. (2013). Disentangling the effects of team competences, team adaptability, and client communication on the performance of management consulting teams. Long Range Planning, 46(3), 258-286

Krajhanzl, J. (2010). Environmental and proenvironmental behavior. School and Health, 21, 251-74.

Lai, C. K., \& Cheng, E. W. (2016). Green purchase behavior of undergraduate students in Hong Kong. Soc. Sci. J., 53(1), 67-76.

Landon, A. C., Woosnam, K. M., \& Boley, B. B. (2018). Modeling the psychological antecedents to tourists' pro-sustainable behaviors: An application of the value-beliefnorm model. Journal of Sustainable Tourism, 26(6), 957-972.

Lee, J., Bhatt, S., \& Suri, R. (2018). When consumers penalize not so green products. 
Psychology ans Marketing, 35(1), 36-46.

Lee, J. S., Hsu, L. T., Han, H. \& Kim, Y. (2010). Understanding how consumers view green hotels: How a hotel's green image can influence behavioural intentions. Journal of Sustainable Tourism, 18(7), 901-914.

Lee, W. H. \& Cheng, C. C. (2018). Less is more: A new insight for measuring service quality of green hotels. International Journal of Hospitality Management, 68(2), 32-40.

Leischnig, A., \& Kasper-Brauer, K. (2015). Employee adaptive behavior in service enactments. Journal of Business Research, 68(2), 273-280.

Lin, P. C., \& Huang, Y. H. (2012). The influence factors on choice behavior regarding green products based on the theory of consumption values. Journal of Cleaner Production, 22(1), 11-18.

Line, N. D., \& Hanks, L. (2016). The effects of environmental and luxury beliefs on intention to patronize green hotels: The moderating effect of destination image. Journal of Sustainable Tourism, 24(6), 904-925.

Llanos-Contreras, O., \& Alonso-Dos-Santos, M. (2018). Exploring the asymmetric influence of socioemotional wealth priorities on entrepreneurial behaviour in family businesses. European Journal of International Management, 12(5-6), 576-595.

Malhotra, N. K., Kim, S. S., \& Patil, A. (2006). Common method variance in IS research: A comparison of alternative approaches and a reanalysis of past research. Management Science, 52, 1865-1883.

Manaktola, K., \& Jauhari, V. (2007). Exploring consumer attitude and behaviour towards green practices in the lodging industry in India. International Journal of Contemporary Hospitality Management, 19(5), 364-377.

Martinez Garcia de Leaniz, P., Herrero Crespo, A. and Gómez López, R. (2018). Customer responses to environmentally certified hotels: The moderating effect of environmental consciousness on the formation of behavioral intentions. Journal of Sustainable Tourism, 26(7), 1160-1177.

Milfont, T. L., \& Sibley C. G. (2012). The Big Five personality traits and environmental engagement: Associations at the individual and societal level. Journal of Environmental Psychology, 32,187-195.

Moghavvemi, S., Woosnam, K. M., Paramanathan, T., Musa, G., \& Hamzah, A. (2017). The effect of residents' personality, emotional solidarity, and community commitment on support for tourism development. Tourism Management, 63(2), 242-254.

Morren, M., \& Grinstein, A. (2016). Explaining environmental behavior across borders: A meta-analysis. Journal of Environmental Psychology, 47(2), 91-106.

Moscardo, G. \& Hughes, K. (2018). All aboard! Strategies for engaging guests in corporate responsibility programmes. Journal of Sustainable Tourism, 23(4), 1-16. 
Nguyen, T. N., Lobo, A., \& Greenland, S. (2016). Pro-environmental purchase behaviour: The role of consumers' biospheric values. Journal of Retailing and Consumer Services, 33, 98-108.

Olya, H. G., \& Al-Ansi, A. (2018). Risk assessment of halal products and services: implication for tourism industry. Tourism Management, 65, 279-91.

Olya, H. G., \& Y. Gavilyan. (2017). Configurational models to predict residents' support for tourism development. Journal of Travel Research, 56(7), 893-912.

Olya, H. G., Z. Altinay Gazi, F. Altinay Aksal, \& Altinay, M. (2018). Behavioral intentions of disabled tourists for the use of peer-to-peer accommodations: An application of fsQCA. International Journal of Contemporary Hospitality Management, 30(1), 1-27.

Olya, H., Khaksar, E. S., \& Alipour, H. (2017). Pro-tourism and anti-tourism community groups: Recipes for support tourism development and its negation in a world heritage site in Turkey. Current Issues in Tourism, 228(1),1-23.

Olya, H., Altinay, L., \& De Vita, G. (2018). An exploratory study of value added services. Journal of Service Marketing, 25(4), 1-23.

Olya, H.G., \& Akhshik, A. (2019). Tackling the complexity of the pro-environmental behavior intentions of visitors to turtle sites. Journal of Travel Research, 58(2), 313-332.

Pappas, I. O., Kourouthanassis, P. E., Giannakos, M. N., \& Chrissikopoulos, V. (2016). Explaining online shopping behavior with fsQCA: The role of cognitive and affective perceptions. Journal of Business Research, 69(2), 794-803.

Pappas, N., \& Papatheodorou, A. (2017). Tourism and the refugee crisis in Greece: Perceptions and decision-making of accommodation providers. Tourism Management, 63(2), 3141.

Peng, N., \& Chen, A. (2019). Luxury hotels going green-the antecedents and consequences of consumer hesitation. Journal of Sustainable Tourism, 34(7),1-19.

Piriyapada, S., \& Wang, E. (2015). Modeling willingness to pay for coastal tourism resource protection in Ko Chang Marine National Park, Thailand. Asia Pacific Journal of Tourism Research, 20(5), 515-540.

Radwan, H. R., Jones, E. \& Minoli, D. (2012). Solid waste management in small hotels: A comparison of green and non-green small hotels in Wales. Journal of Sustainable Tourism, 20(4), 533-550.

Ragin, C. C., \& Davey, S. (2014). Fuzzy-set/Qualitative Comparative Analysis 2.5. Irvine, California: Department of Sociology, University of California.

Rahman, I., Chen, H. \& Reynolds, D. (2020). Evidence of green signaling in green hotels. International Journal of Hospitality Management, 85(6), 102-444.

Rahman, I., \& Reynolds, D. (2016). Predicting green hotel behavioral intentions using a theory of environmental commitment and sacrifice for the environment. International Journal of Hospitality Management, 52(2), 107-116.

Roberts, M., Hanley, N. \& Cresswell, W. (2017). User fees across ecosystem boundaries: Are 
SCUBA divers willing to pay for terrestrial biodiversity conservation? Journal of Environmental Management, 200(2), 53-59.

Ryan, G. W., \& Bernard, H. R. (2003). Techniques to identify themes. Field Methods, 15(1), 85-109.

Schuhmann, P. W., Skeete, R., Waite, R., Lorde, T., Bangwayo-Skeete, P., Oxenford, H. A., Gill, D., Moore, W., \& Spencer, F. (2019). Visitors' willingness to pay marine conservation fees in Barbados. Tourism Management, 71(2), 315-326.

Seetaram, N., Song, H., Ye, S., \& Page, S. (2018). Estimating willingness to pay air passenger duty. Annals of Tourism Research, 72, 85-97.

Sheth, J. N., Newman, B. I., \& Gross, B. L. (1991). Why we buy what we buy: A theory of consumption values. Journal of Business Research, 22(2), 159-170.

So, K. K .F., Oh, H., \& Min, S. (2018). Motivations and constraints of Airbnb consumers: Findings from a mixed-methods approach. Tourism Management, 67, 224-236.

Steg, L., \& De Groot, J. (2010). Explaining prosocial intentions: Testing causal relationships in the norm activation model. British Journal of Social Psychology, 49(4), 725-743.

Steg, L., Bolderdijk, J. W., Keizer, K., \& Perlaviciute, G. (2014). An integrated framework for encouraging pro-environmental behaviour: The role of values, situational factors and goals. Journal of Environmental Psychology, 38(5), 104-15.

Stern, P.C., Dietz, T., Abel, T., Guagnano, G.A., \& Kalof, L. (1999). A value-belief-norm theory of support for social movements: The case of environmentalism. Human Ecology Review, 36(\&), 81-97.

Tang, C. M. F., \& Lam, D. (2017). The role of extraversion and agreeableness traits on Gen Y's attitudes and willingness to pay for green hotels. International Journal of Contemporary Hospitality Management, 29(1), 607-623.

Tashakkori, A., \& Creswell, J. W. (2007). Editorial: The new era of mixed methods. Journal of Mixed Methods Research, 1(1), 3-7.

Tashakkori, A., \& Teddlie, C. (2003). Handbook of mixed methods in social \& behavioral research. Thousand Oaks, CA: Sage Publications.

Testa, F., \& Iraldo, F. (2010). Shadows and lights of GSCM (green supply chain management): Determinants and effects of these practices based on a multinational study. J. Clean. Prod, 18(10-11), 953-962.

Tully, S. M., \& Winer, R. S. (2014). The role of the beneficiary in willingness to pay for socially responsible products: A meta-analysis. Journal of Retailing, 90(2), 255-274.

Wang, J., Wang, S., Wang, Y., Li, J., \& Zhao, D. (2018). Extending the theory of planned behavior to understand consumers' intentions to visit green hotels in the Chinese context. International Journal of Contemporary Hospitality Management, 30(8), 28102825. 
Wang, P. W., \& Jia, J. B. (2012). Tourists' willingness to pay for biodiversity conservation and environment protection, Dalai Lake protected area: Implications for entrance fee and sustainable management. Ocean and Coastal Management, 62, 24-33.

Wei, S., Ang, T., \& Jancenelle, V. E. (2018). Willingness to pay more for green products: The interplay of consumer characteristics and customer participation. Journal of Retailing and Consumer Services, 45(1), 230-238.

Woodside, A. G. (2013). Moving beyond multiple regression analysis to algorithms: Calling for adoption of a paradigm shift from symmetric to asymmetric thinking in data analysis and crafting theory. Journal of Business Research, 66(4), 463-472.

Woodside, A. G. (2014). Embrace• perform• model: Complexity theory, contrarian case analysis, and multiple realities. Journal of Business Research, 67(12), 2495-2503.

Woodside, A. G. (2016). Bad to good: Achieving high quality and impact in your research. Bingley: Emerald Group Publishing.

Wu, P. L., Yeh, S. S., \& Woodside, A. G. (2014). Applying complexity theory to deepen service dominant logic: Configural analysis of customer experience-and-outcome assessments of professional services for personal transformations. Journal of Business Research, 67(8), 1647-1670.

Yadav, R., \& Pathak, G. S. (2017). Determinants of consumers' green purchase behavior in a developing nation: Applying and extending the theory of planned behavior. Ecological Economics, 134(1), 114-122.

Yadav, R., Balaji, M. S., \& Jebarajakirthy, C. (2019). How psychological and contextual factors contribute to travelers' propensity to choose green hotels? International Journal of Hospitality Management, 32(5), 29-43.

Zach, S., \& Lissitsa, S. (2016). Internet use and leisure time physical activity of adults - A nationwide survey. Computers in Human Behavior, 60(2), 483-491.

Zhao, R., Geng, Y., Liu, Y., Tao, X., \& Xue, B. (2018). Consumers' perception, purchase intention, and willingness to pay for carbon-labeled products: A case study of Chengdu in China. Journal of Cleaner Production, 171(4), 1664-1671. 